\title{
$\mathrm{PH} 96$
}

\section{La Red Nacional de Maestros de la Construcción Tradicional}

\begin{abstract}
En 2016 nace la Red Nacional de Maestros de la Construcción Tradicional, desarrollada desde INTBAU en colaboración con el IPCE y con el apoyo del Richard H. Driehaus Charitable Lead Trust. Surge de la necesidad, detectada en España, de contar con un directorio de buenas prácticas que recogiera información sobre los principales maestros de la construcción tradicional en activo, concebido no solo como una herramienta de registro del trabajo artesanal, sino también como una base de datos didáctica, donde se explicaran y pusieran en valor los procesos propios de las distintas actividades.
\end{abstract}

Alejandro García Hermida | coordinador de las iniciativas INTBAU en España

URL <http://www.iaph.es/revistaph/index.php/revistaph/issue/view/4259>

La Red Internacional para la Construcción, la Arquitectura y el Urbanismo Tradicionales, INTBAU, tiene por objetivos el estudio, la promoción y la continuación de las tradiciones constructivas y arquitectónicas. El Richard $\mathrm{H}$. Driehaus Charitable Lead Trust, por su parte, es una entidad sin ánimo de lucro norteamericana. Juntos colaboran en proyectos relacionados con el fomento de la arquitectura y la construcción tradicionales y la conservación del patrimonio.

En este contexto han trabajado para desarrollar un directorio nacional con información sobre los principales maestros de la construcción tradicional que se mantienen en activo, de manera que puedan estar al alcance de posibles clientes interesados en su trabajo o en recibir formación. A menudo al desconocimiento de los oficios tradicionales se suma la falta de difusión de las pequeñas empresas, que no pueden competir en presencia publicitaria y accesibilidad con la gran industria, y muy especialmente en Internet, donde tener una buena y bien posicionada web suele estar fuera de su alcance.

La Red se concreta en una plataforma web, www.redmaestros.com, de libre acceso, en la que se puede localizarse ya un gran número de maestros de la construcción tradicional y su restauración. Durante su puesta en marcha se han identificado más de 2.000 profesionales, entre los cuales, tras un proceso de evaluación, han sido seleccionados más de 370 , que ya cuentan con su perfil en el directorio web. Cada perfil incluye la información de contacto, una descripción tanto de los tipos de

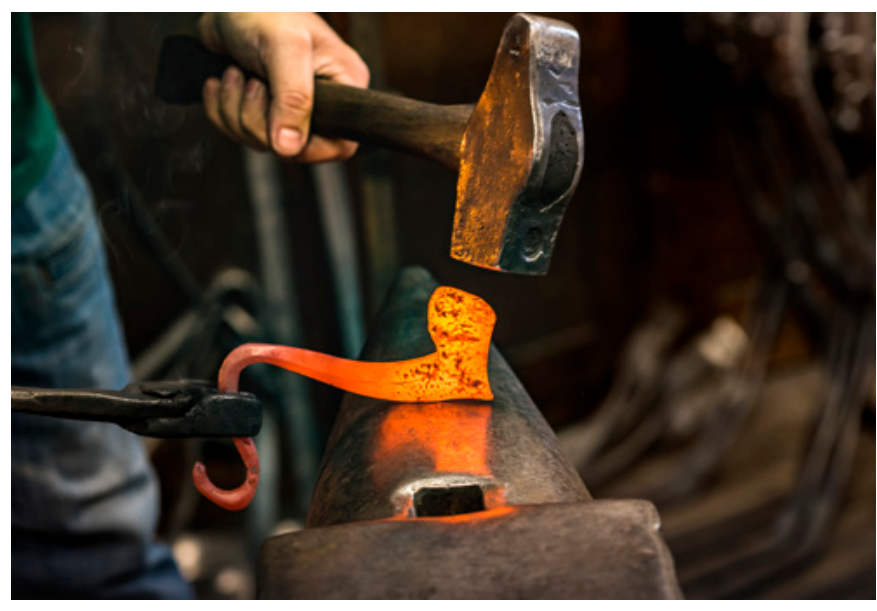

Proceso de forjado de los bancos de la Sagrada Familia | foto cedida por Enric Pla Montferrer

trabajo que realiza como de las técnicas que utiliza en el desempeño de su labor, una relación de sus obras más destacadas, y una explicación de cómo fue su aprendizaje y de si ha formado a algún aprendiz, además de fotografías y/o vídeos tanto de sus trabajos como de sus procesos de ejecución, procurando siempre que todo resulte lo más visual y accesible posible.

El objetivo es acercar los oficios tradicionales a la sociedad, contribuyendo así a su conocimiento y valoración. También se busca favorecer el incremento de la demanda de su trabajo y apoyar de este modo la continuidad y transmisión de este tipo de saber. No menos importante es que aquellos arquitectos o técnicos que tengan que enfrentarse a un trabajo de restauración de un bien patrimonial o a una nueva construcción en 


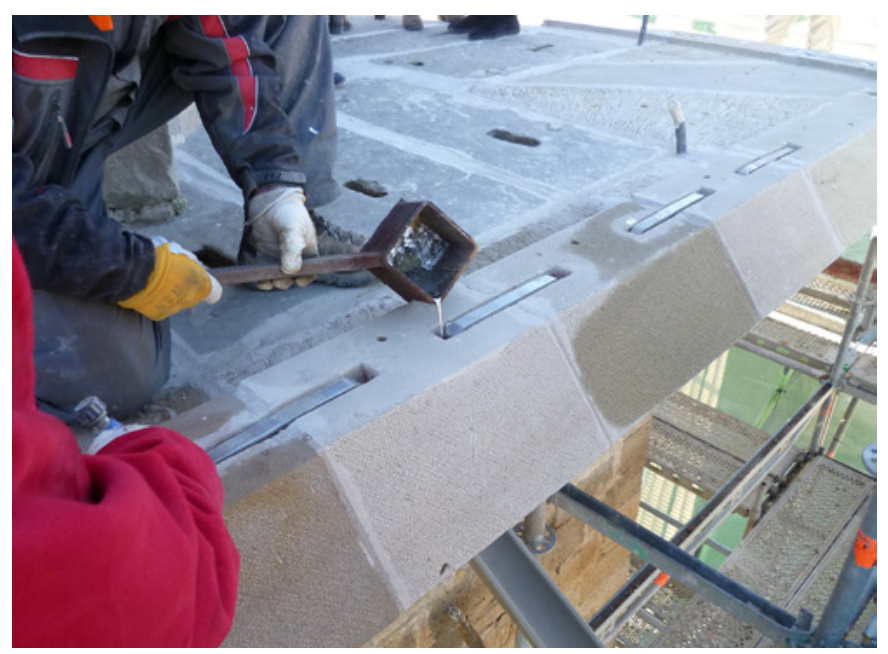

Emplomado de uniones metálicas en la sillería de la Iglesia de San Pedro de Olite | foto cedida por Cantería Jaurrieta

entornos de especial valor puedan localizar fácilmente a los mejores expertos y asesorarse para realizarlo satisfactoriamente.

La colaboración entre INTBAU y Richard H. Driehaus Charitable Lead Trust no se limita la Red de Maestros Artesanos, sino que viene desde 2012. La primera de las iniciativas promovidas en nuestro país por la fundación fue el Premio Rafael Manzano de Nueva Arquitectura Tradicional.

El galardón tiene por fin honrar a arquitectos en activo en España o en Portugal cuyo conjunto de obras haya destacado en la continuación y actualización de nuestras tradiciones arquitectónicas. A este premio siguieron la organización anual de múltiples cursos, conferencias, seminarios y exposiciones, así como la puesta en marcha desde el año 2016 del Concurso de Arquitectura Richard $\mathrm{H}$. Driehaus y de los Premios Richard H. Driehaus de las Artes de la Construcción. El primero está dirigido a promover entre los municipios y jóvenes arquitectos españoles un tipo de arquitectura que respete las formas, los materiales y las técnicas de la tradición constructiva. El segundo, a honrar a los principales maestros en activo de los oficios tradicionales de la construcción. Este último galardón se acompaña de becas formativas anuales que fomentan la transmisión de conocimiento entre maestros y aprendices. 